\title{
Effect of biostimulation and estrus synchronization on estrus response and fertility rate in primiparous and multiparous Kundhi buffaloes
}

Qudratullah Kalwar ${ }^{1,4^{*}}$, Akeel Ahmed Memon ${ }^{2}$, Asmatullah Kaka², Nazar Ali Korejo ${ }^{2}$, Yar Muhammad Jalbani ${ }^{3,4}$, Rashid Ali Korejo ${ }^{4}$, Tarique Ahmed Khokhar ${ }^{4}$, Muhammad Mohsen Rahimoon ${ }^{4}$ and Arab Khan Lund ${ }^{4}$

1. Lanzhou Institute of Husbandry and Pharmaceutical Sciences, Chinese Academy of Agricultural Science, Lanzhou 730050, Gansu-China

2. Faculty of Animal Husbandry and Veterinary Sciences, Sindh Agriculture University Tandojam-Pakistan

3. Institude of Quality Standard and Testing Technology for Agro Products-China

4. Shaheed Benazir Bhutto University of Veterinary and Animals Sciences, Sakrand, Sindh-Pakistan

*Corresponding author's email:qudratullahkalwar@gmail.com

Citation

Qudratullah Kalwar, Akeel Ahmed Memon, Asmatullah Kaka, Nazar Ali Korejo, Yar Muhammad Jalbani, Rashid

Ali Korejo, Tarique Ahmed Khokhar, Muhammad Mohsen Rahimoon and Arab Khan Lund. Effect of

biostimulation and estrus synchronization on estrus response and fertility rate in primiparous and multiparous

Kundhi buffaloes. Pure and Applied Biology Vol. 8, Issue 2, pp1077-1083.

http://dx.doi.org/10.19045/bspab.2019.80049

\begin{tabular}{llll}
\hline \hline Received: 14/01/2019 & Revised: 21/03/2019 & Accepted: 28/03/2019 & Online First: 05/04/2019 \\
\hline
\end{tabular}

\section{Abstract}

Anestrus and unobserved estrus are one of the crucial managemental lapses in the livestock business. This research was planned to assess the efficiency of different estrus synchronization procedures with bull exposed and with non-bull exposed groups in primiparous and multiparous buffaloes at Kundhi buffalo farm Rorhi and its surroundings. Total 40 ( $n=20$ primiparous, $n=20$ multiparous) buffaloes were used in this study. The chosen buffaloes were divided into two main groups, A (BE, Bull-Exposed) and group B (NE, Non-Exposed). Based on the treatments A group was further sub-divided into two sub-groups, OvSynch bull-exposed (OBE) A1 and prostaglandin bull exposed (PBE) A2. Also, B group was parted into dual sub-groups Ovsynch non-exposed (ONE) and prostaglandin non-exposed (PNE) group B2. Results of the present study showed that estrus response differed significantly among the primiparous and multiparous Kundhi buffalo in all groups $(\mathrm{P}<0.05)$. The overall estrus response $(50 \%$ and $100 \%)$ and pregnancy rates (40\% and 70\%) were higher in both primiparous and multiparous animals of BE groups as compared to primiparous (60\% and 70\%), and multiparous animals (30\% and 60\%) of NE groups. The overall estrus, duration was also higher in the primiparous ( $22 \pm 0.66$ hours) and multiparous animals (20 \pm 2.05 hours) of BE groups, in contrast to $16 \pm 0.95$ hours and $14 \pm 0.84$ hours of NE groups. These findings suggested that the use of bull with OvSynch protocol it could efficiently be used to improve the estrus incidence and pregnancy rate in primiparous and multiparous buffaloes as compararion double prostaglandin protocol.

Keywords: Biostimulation; Estrus synchronization; Estrus response; Kundhi buffalo; Pregnancy rate 


\section{Introduction}

Reproductive performance of an animal is a crucial factor in the livestock business. There are many factors which hinder the reproductive performance of an animal. Amongst these, anestrus or unobserved estrus is the prominent one. In anestrus, there is complete sexual inactivity with no manifestation of heat. The ovary becomes inactive and normal cyclic activities are seen to be immobile in this condition. There are several causes of anestrus, e.g., hormonal imbalance, poor nutrition, acquired abnormalities of the female reproductive system and seasonal changes [1].

Estrus Synchronization (ES) is one of the solutions to overcome these problems. Reproductive performance of female animals can be enhanced by the use of ES. Numerous ES techniques have been developed previosly in animals for the improvement of estrus response and fertility rate [2-4]. In these ES practices progesterone, prostaglandin, $\mathrm{GnRH}$, and estrogens alone or in numerous combinations are used $[5,6]$. ES involves manipulating the estrous cycle to cause as many females as possible to enter estrus at a specific time. The first efforts to do so began in the late 1960 s by administering oral progesterone and an estrogen injection [7]. Since then numerous estrous synchronization protocols are continued to be developed to facilitate the usage of artificial insemination and for the improvement of the reproductive proficiency of farm animals. Estrus Synchronization and artificial insemination are two of the most significant management practices available to producers to increase the reproductive performance of their animals [8].

Bio stimulation may be defined as a male stimulatory effect on estrus response and ovulation rate in the female via pheromones [9]. Pheromones are defined as airborne chemicals released from the feces, cutaneous glands or from urine, that are sensed by the respiratory or olfactory systems that cause endocrine response and behavioral changes [10]. In male animals, pheromones are largely released from urine and they affect on hypothalamic-pituitary-adrenal (HPA) activity of female animals [11, 12]. It has been stated by exposing the cows to bulls (biostimulation) before, during, and after a GnRH-based ES protocol following fixed timed artificial insemination improved pregnancy rate in bovine animals [13, 14]. However, information related to the effects of bull exposure combination with estrus synchronization in primiparous and multiparous Kundhi buffaloes is scarce. Therefore, the current research was established, with the goal to evaluate the biostimulatory effect of bulls to improve the estrus response \& fixed-timed artificial insemination pregnancy rate in primiparous and multiparous Kundhi buffaloes using different estrous synchronization protocols.

\section{Materials and methods}

\section{Animals and their management}

Total $40 \quad(n=20 \quad$ primiparous, $n=20$ multiparous) buffaloes were used in this study. These animals were raised on semi intensive managemental circumstances at Kundhi Farm Rohri and its surroundings. Before the start of experiment all the buffaloes were confirmed nonpregnant by rectal palpation.

\section{Experimental design}

The chosen buffaloes were divided into two main groups, A (BE, Bull-Exposed) and group B (NE, Non-Exposed). Based on the treatments A group was further sub-divided into two sub-groups, OvSynch bull-exposed (OBE) A1 and in prostaglandin bull exposed (PBE) A2. Similarly, B group was parted into two sub-groups ovSynch non-exposed (ONE) and prostaglandin non-bull exposed (PNE) group B2. 


\section{Sub-group-A-1.OvSynch Bull Exposed (OBE) group $n=10$}

Estrus Synchronization was implemented with the OvSynch protocol, in which $02 \mathrm{ml}$ GnRH on day 0 and 9 th and $05 \mathrm{ml}$ PGF2 $\alpha$ was injected on day 7 , and also these buffaloes were exposed to an aproned bull two times a day i.e. at 6 am and $6 \mathrm{pm}$ for half an hour, from the starting of experiment to artificial insemination.

Sub-group-A2. Prostaglandin F2 $\alpha$ BullExposed (PBE) group $n=10$

In this group double PGF2 $\alpha$ was injected at the interval of 11-days. After injection of PGF $2 \alpha$, these animals were also exposed to an intact, aproned bull for 30 minutes, two times in a day (6am, and $6 \mathrm{pm}$ ) from the starting of treatment till artificial insemination.

\section{Sub-group-B-1.OvSynch Non Bull} Exposed (ONE) group $n=10$

Synchronization was performed in these animals with a similar procedure, as used in the animals of group A-1. But the animals of this group were not exposed to bull from the start of experiment till artificial insemination.

Sub-group-B-2.Prostaglandin F2a NonExposed (PNE) group $n=10$

The treated animals were not exposed to the bull, but synchronization was performed with a similar method, as recived by subgroup B2 animals.

\section{Estrus detection}

Group A-1 and B-1 animals were observed after the injection of $2^{\text {nd }} \mathrm{GnRH}$ for behavioral changes to confirm the heat. However, animals of group A-2 and B-2 were watched closely after $2^{\text {nd }}$ PGF $2 \alpha$ inoculation to check the estrus. In group A1 and B1 artificial insemination was performed two times i.e. 12 and, 24 hours after the last gonadotropin inoculation. While artificial insemination was done after 72 and 96 hours in A2 and B2 group, following second prostaglandin shot by frozen thawed semen got from Directorate of Animal Breeding, Livestock Department Government of Sindh.

\section{Statistical analysis}

Results were calculated by using graph pad instate 3.05 versions of the statistics through Chi square test and ANOVA. The significant was considered to be at $\mathrm{P}<0.05$.

\section{Results}

The current research was carried out to evaluate with or without biostimulation the effectiveness of different protocols of estrus synchronization (ES), in primiparous and multiparous Kundhi buffaloes. The outcomes are existing in the following tables.

\section{Occurrence of estrus}

The effect of estrus synchronisation with and without bull exposure on the appearance of estrus in OvSynch and double prostaglandin F2 $\alpha$ groups in different parities of Kundhi buffaloes are defined in (Table 1). Intensity of estrus significantly $(\mathrm{P}<0.05)$ differed among the primiparous and multiparous Kundhi buffaloes in all groups. Furthermore, higher estrus response (100\%) was detected in all multiparous animals, while primiparious animals showed $(60 \%)$ and $(40 \%)$ in OBE and ONE group respectively, Likewise, OvSynch non-exposed treatment induces higher estrus response in multiparous animals as compare to primiparous respectively. Overall estrus response (Table 2) was observed higher in the primiparous and multiparous animals of $\mathrm{BE},(50 \%)$, (100\%), groups as compared to NE $(60 \%)$, (70\%) groups respectively.

\section{Estrus duration}

The effect of synchronization of estrus with bull exposed and non-bull exposed on duration of oestrus in OvSynch \& double PGF $2 \alpha$ groups in different parities Kundhi buffaloes are presented in (Table 3 ). Duration of estrus significantly $(\mathrm{P}<0.05)$ differed amongst the groups. Overall estrus length was higher in the primiparous $(22 \pm 0.663$ hours) and multiparous animals $(20 \pm 2.05$ hours) of bull exposed groups, as compared 
to the primiparous $(16 \pm 0.954 \mathrm{hrs})$, and multiparous animals (14 $\pm 0.841 \mathrm{hrs})$ of nonbull exposed groups (Table 4). Furthermore, longer estrus duration was prominent in primiparous and multiparous animals of OvSynch bull-exposed group $(23 \pm 0.577$ hours), (20 \pm 2.059 hours) as compared to PGF2 $\alpha$ bull-exposed (21 \pm 1.000 hours), (18 \pm 0.632 hours), Ovsynch non- exposed (16 \pm 1.763 hours $),(15 \pm 1.291$ hours $)$ and PGF2 $\alpha$ non-bull-exposed (16 \pm 1.154 hours $),(14 \pm$ 1.154 hours) groups.

\section{Pregnancy rate}

The results of synchronization of estrus with bull exposed and non bull exposed on pregnancy rate following OvSynch and double prostaglandin F2 $\alpha$ in primiparous and multiparous Kundhi buffaloes are precised in Table 1. Outcomes of estrus synchronisation with bull exposed (BE) and non bull exposed (NE) on the estrus response in OvSynch \& double PGF2 $\alpha$ groups in primiparous and multiparous Kundhi buffaloes

\begin{tabular}{|c|c|c|c|}
\hline Groups & Parity & \multicolumn{2}{|c|}{ Estrus Response (\%) } \\
\hline \multirow{3}{*}{$\mathrm{BE}$} & & OvSynch & Double PGF2 $\alpha$ \\
\cline { 3 - 4 } & Primiparious & $3 / 5(60 \%) \mathrm{c}$ & $2 / 5(40 \%) \mathrm{c}$ \\
$\mathrm{NE}$ & Multiparious & $5 / 5(100 \%) \mathrm{a}$ & $5 / 5(100 \%) \mathrm{a}$ \\
& Primiparious & $3 / 5(60 \%) \mathrm{c}$ & $3 / 5(60 \%) \mathrm{b}$ \\
& Multiparious & $4 / 5(80 \%) \mathrm{b}$ & $3 / 5(60 \%) \mathrm{b}$ \\
\hline
\end{tabular}

Dissimilar superscript within the similar column represents significant results, $\mathrm{P}=0.049$

Table 2. Sound effects of estrus synchronization with bull exposed (BE) and non bull exposed (NE) on the estrus response in OvSynch \& double PGF2 $\alpha$ groups in primiparous and multiparous Kundhi buffaloes

\begin{tabular}{|c|c|c|}
\hline Groups & Parity & Overall Estrus Response (\%) \\
\hline \multirow{2}{*}{ BE } & Primiparious & $5 / 10(50 \%) \mathrm{d}$ \\
& Multiparious & $10 / 10(100 \%) \mathrm{a}$ \\
$\mathrm{NE}$ & Primiparious & $6 / 10(60 \%) \mathrm{c}$ \\
& Multiparious & $7 / 10(70 \%) \mathrm{b}$ \\
\hline
\end{tabular}

Dissimilar superscript within the similar column represents significantly results, $\mathrm{P}=0.045$

Table 3. The effect of synchronization of estrus with bull exposed (BE) and non-bull exposed (NE) on duration of estrus in OvSynch \& double PGF2 $\alpha$ groups in primiparous and multiparous Kundhi buffaloes

\begin{tabular}{|c|c|c|c|}
\hline Groups & Parity & \multicolumn{2}{|c|}{ Estrus duration (hours) } \\
\hline \multirow{3}{*}{ BE } & & Ovsynch & Double PGF2 $\alpha$ \\
\cline { 3 - 4 } & Primiparious & $23 \pm 0.577$ hours $^{\mathrm{a}}$ & $21 \pm 1.000$ hours $^{\mathrm{a}}$ \\
& Multiparious & $20 \pm 2.059$ hours $^{\mathrm{b}}$ & $18 \pm 0.632$ hours $^{\mathrm{b}}$ \\
& Primiparious & $16 \pm 1.763$ hours $^{\mathrm{c}}$ & $16 \pm 1.154$ hours $^{\mathrm{c}}$ \\
& Multiparious & $15 \pm 1.2911$ hours $^{\mathrm{c}}$ & $14 \pm 1.154$ hours $^{\mathrm{d}}$ \\
\hline
\end{tabular}

Dissimilar superscript within the similar column represents significantly results, $\mathrm{P}=0.005$

(Table 5). These results revealed that pregnancy rate significantly $(\mathrm{P}<0.05)$ vary pregnancy rate was greater in the primiparous (40\%) and multiparous (70\%) animals of bull exposed (NE) $(30 \%) \&(60 \%)$ groups (Table $6)$. Furthermore, higher pregnancy rate was identified in the primiparous and multiparous animals of OvSynch bull exposed group $(40 \%) \&(80 \%)$ as compared to prostaglandin F2 $\alpha$ bull exposed (40\%),(60\%) group. However in primiparous and multiparous animals of OvSynch non-exposed (40\%), $(60 \%)$ and prostaglandin F2 $\alpha$ non-bull exposed group were (20\%) \& (60\%) respectively.

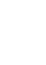

.

.


Table 4. The effect of synchronization of oestrus with bull exposed (BE) and non-bull exposed (NE) on overall duration of estrus in OvSynch \& double PGF2 $\alpha$ groups in primiparous \& multiparous Kundhi buffaloes

\begin{tabular}{|c|c|c|}
\hline Groups & Parity & Over all Estrus duration (hours) \\
\hline & & $22 \pm 0.663$ hours $^{\mathrm{a}}$ \\
BE & Primiparious & $20 \pm 2.05$ hours $^{\mathrm{b}}$ \\
& Multiparious & $16 \pm 0.954$ hours $^{\mathrm{c}}$ \\
& Primiparious & $14 \pm 0.841$ hours $^{\mathrm{d}}$ \\
\hline
\end{tabular}

Dissimilar superscript within the similar column represents significant results, $\mathrm{P}=0.039$

Table 5. The results of synchronization of estrus with bull exposed and non bull exposed on the pregnancy rate fallowing ovSynch and double prostaglandin F2 $\alpha$ in primiparous and multiparous Kundhi buffaloes

\begin{tabular}{|c|c|c|c|}
\hline Groups & Parity & \multicolumn{2}{|c|}{ Pregnancy rate (\%) } \\
\hline \multirow{3}{*}{$\mathrm{BE}$} & & OvSynch & Double PGF2 $\alpha$ \\
\cline { 3 - 4 } & Primiparious & $2 / 5(40 \%) \mathrm{c}$ & $2 / 5(40 \%) \mathrm{c}$ \\
$\mathrm{NE}$ & Multiparious & $4 / 5(80 \%) \mathrm{a}$ & $3 / 5(60 \%) \mathrm{a}$ \\
& Primiparious & $2 / 5(40 \%) \mathrm{c}$ & $1 / 5(20 \%) \mathrm{c}$ \\
& Multiparious & $3 / 5(60 \%) \mathrm{b}$ & $3 / 5(60 \%) \mathrm{b}$ \\
\hline
\end{tabular}

Dissimilar superscript within the similar column represents significant results, $\mathrm{P}=0.049$

Table 6. Effect of estrus synchronization with and without bio-stimulation on overall pregnancy rate in primiparous and multiparous Kundhi buffaloes

\begin{tabular}{|c|l|c|}
\hline Groups & Parity & Overall pregnancy rate (\%) \\
\hline \multirow{2}{*}{$\mathrm{BE}$} & Primiparious & $4 / 10(40 \%) \mathrm{c}$ \\
& Multiparious & $7 / 10(70 \%) \mathrm{a}$ \\
$\mathrm{NE}$ & Primiparious & $3 / 10(30 \%) \mathrm{d}$ \\
& Multiparious & $6 / 10(60 \%) \mathrm{b}$ \\
\hline
\end{tabular}

Dissimilar superscript within the similar column represents significant results, $\mathrm{P}=0.038$

\section{Discussion}

Reproductive insufficiency remains one of the significant hitches to the dairy farmers, which reduces the production. Efforts are being made by researchers to improve the reproductive performance of the females [15]. Several approaches have been applied to achieve the maximum reproductive performance, and it has been found that the use of hormones effectively reduces calving interval, and bring animals in estrus at the desired time thus improving reproductive performance [16, 17]. In all groups, multiparous animals showed higher estrus responses as compared to primiparous animals, and estrus response differed significantly among the groups $(\mathrm{P}<0.05)$. These findings are in disagreement with Khanh et al. [11] who reported that the response of estrus did not significantly differed between the primiparous and multiparous cows while they found higher estrus response in multiparous animals as compared to primiparous animals. Our findings are better than Ghosh et al. [8] who reported $38.9 \%$ estrous response in heifers and $77.7 \%$ in multiparous cattle. Some factors could be familiar to this outcome; different synchronization treatments may induce different physiological responses and 
could show a significant variation in results. In the present research prostaglandin and OvSynch method of estrus synchronization were used whereas Ghosh et al. [8] used ovSynch synchronization treatment Khanh et al. [11] used controlled internal drug releasing device (CIDR) estrus synchronization treatment. In both cases estrus response and estrus duration, the effect may also be differed due to the difference in the species. Cows respond to treatment might be in a different manner as compared to buffaloes.

Estrus duration was higher in the primiparous and multiparous animals of both treated bullexposed groups as compared to non-exposed groups. These results are in agreement with Khanh et al. [11] for the primiparous cows but not for multiparous. However, in another study by Flores et al. [18] who reported that reported the primiparous cows represent low estrus duration as compared to multiparous cows. The difference observed between the present study, and the above mentioned two studies may be due to the different breeds and environment. In different environmental condition and in the breeds the esrus response varies. In current findings, duration of estrus was apparent in primiparous $(22 \pm 0.663$ hours) and multiparous $(20 \pm 2.05$ hours $)$ animals of bull-exposed group followed by primiparous ((16 \pm 0.954 hours $)$ and multiparous (14 \pm 0.841 hours) animals nonbull exposed group respectively. Our results of estrus duration are greater than those stated by Roeflos et al. [19] who declared that duration of estrus in primiparous is 13.6 hours and in multiparous animals 10.8 hours. These alterations in findings may be due to different environmental conditions, type of housing, how estrus was detected, and the frequency of handling.

In all groups, a significantly higher pregnancy rate was noted in multiparous animals as compared to primiparous animals. The present findings are similar to the Khanh et al. [11] who observed a higher pregnancy rate in multiparous animals as compared to primiparous animals. But they reported the non-significant difference in pregnancy rate among the primiparous and multiparous cows. Murugavel et al. [20] reported $57.6 \%$ conception rate in multiparous cows and $40.6 \%$ in primiparous with progesterone based estrus synchronization treatment. While in current study high conception rate was observed in multiparous buffaloes $(80 \%)$ and $(60 \%)$, while in primiparous $(40 \%)$ conception rate was observed in case of OvSynch bull exposed and prostaglandin F2 $\alpha$ bull exposed group respectively.

\section{Conclusion}

This study concluded that the use of bull with OvSynch protocol of estrus synchronization could efficiently be used to improve the response of estrus and fertility rate in primiparous and multiparous Kundhi buffaloes as compare to prostaglandin group.

\section{Authors' contributions}

Conceived and designed the experiments: Q Kalwar, AA Memon \& A Kaka, Performed the experiments: Q Kalwar \& AA Memon, Analyzed the data, YM Jalbani, RA Korejo \& TA Khokhar, Contributed reagents/ materials/ analysis tools: MM Rahimoon, NA Korejo \& AK Lund, Wrote the paper: Q Kalwar \& AA Memon.

\section{References}

1. Ahmad S, Kumar H, Singh G \& Patra MK (2011). The administration of GnRH plus $\mathrm{PGF}_{2}$ alpha synchronizes the estrous in anestrous crossbred cows expose to bull urine. Ind J Vet Res 20(1): 42-45.

2. Baruselli PS, Reis EL, Marques MO, Nasser and LF \& Bo GA (2004). The use of the hormonal treatments to improve reproductive performance of anestrous beef cattle in a tropical climate. Anim Repro Sci 82-83: 479-486.

3. Bridges GALA, Helser DE, Grum, Mussard ML, Gasser CL and Day M L (2008). Decreasing the interval between GnRH and PGF $2 \alpha$ from 7 to 5 days and lengthening proestrus increases timed-AI pregnancy 
rates in beef cows. Theriogenol 69: 843851.

4. Claro IJO, SáFilho G, Peres RF, Aono FH, Day ML \& Vasconcelos JL (2010). Reproductive performance of prepubertal Bos indicus heifers after progesterone basedtreatments. Theriogenol 74: 903-911.

5. Brito LFC, Satrapa R, Marson EP \& Kastelic JP (2006). Efficacy of PGF2 $\alpha$ to Synchronize Estrus in water buffalo cows (Bubalus bubalis) is dependent upon plasma progesterone concentration, corpus luteum size, and ovarian follicular status before treatment. J Anim Sci 44: 154-159.

6. Cerri RLJE, Santos SO, Juchem K, Galvao N \& Chebel RC (2004). Timed artificial insemination with estradiol cypionate or insemination estrus in high-producing dairy cows. J Dairy Sci 87: 3704-3715.

7. Wiltbank JN \& Kasson CW (1968). The synchronization of estrus in Cattle with an oral progestational agent and an injection of estrogen. J Anim Sci 27(1): 113-116.

8. Ghosh T, Paul AK, Talukder AK. Alam MGS and Bari FY (2012). Use of Two Estrus Synchronization Protocols and Their Success on Pregnancy in Zebu and Crossbred Heifers at Char Areas of Bangladesh. J Embr Trans 27(4): 223-228.

9. Chenoweth PJ (1983). Reproductive management procedures in control of breeding. Anim prod Aust 15: 28.

10. Rekwot PI., Ogwy D \& Oyedipe E (2000). Influence of bull stimulation, season and parity on the resumption of ovarian activity of zebu (Bos indicus) cattle following parturition. J Anim Rep Sci 63: 1-11.

11. Khanh NP, Roshina Y, Ornar MA, Dhaliwal GD, Wahid H, Kumaran AM, Yap KC, Fahmi M \& Azmil A (2012). The effect of biostimulation on estrus behaviour, ovulation time and conception rate in primiparous and multiparous beef cows. $J$ of Vet and Anim Adv 11(3): 404-411.

12. Mora OA \& Sanchez-Criado JE (2004). Involvement of the cortical adrenal hormones in the pheromonal restoration activity in ageing rats. Life Sci 74: 3285-90.
13. Berardinelli JG, Joshi PS and Tuck SA (2007). Conception rates to artificial insemination in primiparous suckled cows exposed to the biostimulatory effect of bulls before, and during a gonadotropin-releasing hormone-based estrus synchronization protocol. J Anim Sci. 85: 848-852.

14. Tauck SA, Olsen JR, Wilkinson JRC \& Berardinelli JG (2010). Duration of daily bull exposure on the resumption of ovulatory activity in postpartum, primiparous, suckled beef cows. Anim Repro Sci 118(1): 13-18.

15. Singh S, Wani NA \& Maurya SN (2003). Use of different hormones for the treatment of postpartum anestrous in buffaloes under field condition. Ind J Anim Sci 73: 894-896.

16. Mehmood MU, Mehmood S, Riaz A, Ahmad N \& Sattar A (2012). The superovulatory response in summer anestrus buffaloes and cattle treated with Estrus Synchronization protocol. Anim and Plant Sci 22: 888-893.

17. Neglia G, Gasparrini B, Palo RD, Rosa CD \& Zicarelli L (2008). Comparison of pregnancy rates with two estrus synchronization protocols in Italian Mediterranean Buffalo cows. Anim Repro 45: $120-125$.

18. Flores R, Looper ML, Kreider DL, Post NM \& Rosenkrans CF (2006). Estrous behaviour and initiation of estrous cycles in postpartum Brahman-influenced cows after treatment with progesterone and prostaglandin $\mathrm{F} 2 \alpha . J$ Anim Sci 84: 1916-1925.

19. Roeflos J, VanEerdenburg FJCN, Soede NM \& Kemp B (2005). Various behavioural signs of estrus and their relationship with time of ovulation in dairy cattle. Theriogenol 63: 1366-1377.

20. Murugavel K, Antoine D, Raju MS \& Lo'pez-Gatius F (2009). The effect of the addition of equine chorionic gonadotropin to a progesterone-based estrous synchronization protocol in buffaloes (Bubalus bubalis) under tropical conditions. Theriogenol 71: 1120-1126. 